\title{
ULEARN: Personalised Learner's Profile Based On Dynamic Learning Style Questionnaire
}

\author{
Shaimaa M. Nafea \\ School of Business \\ Arab Academy for Science \\ Technology and Maritime \\ Cairo, Egypt \\ Email: P15017421@my365.dmu.ac.uk
}

\author{
François Siewe \\ School of Computer Science \\ and Informatics \\ De Montfort University \\ Leicester, LE1 9BH \\ United Kingdom \\ Email: fsiewe@dmu.ac.uk
}

\author{
Ying $\mathrm{He}$ \\ School of Computer Science \\ and Informatics \\ De Montfort University \\ Leicester, LE1 9BH \\ United Kingdom \\ Email: ying.he@dmu.ac.uk
}

\begin{abstract}
E-Learning recommender system effectiveness relies upon their ability to recommend appropriate learning contents according to the learner learning style and preferences. An effective approach to handle the learner preferences is to build an efficient learner profile in order to gain adaptation and individualisation of the learning environment. It is usually necessary to know learning style and preferences of the learner on a domain before adapting the learning process and course content. This study focuses on identifying the learning styles of students in order to adapt the learning process and course content. ULEARN is an adaptive recommender learning system designed to provide learners with personalised learning environment such as course learning objects that match their adaptive profile. This paper presents the algorithm used in ULEARN to reduce dynamically the number of questions in Felder-Silverman learning style questionnaire used to initialise the adaptive learner profile. Firstly, the questionnaire is restructured into four groups, one for each learning style dimension; and a study is carried out to determine the order in which questions will be asked in each dimension. Then an algorithm is built upon this ranking of questions to calculate dynamically the initial learning style of the user as they go through the questionnaire.
\end{abstract}

Keywords-E-learning; adaptive-learning; algorithms; adaptive learner profile; learning style; felder-silverman model; questionnaire; profiler.

\section{INTRODUCTION}

Over the last few decades, the WWW has turned into a noteworthy source of information and a built up platform for education and entertainment. Nonetheless, this remarkable growth in the information available has led to information overload, as navigating through and finding relevant information has become more and more challenging. Personalisation has been widely used throughout the past few years to overcome this [1] [2]. Learners frequently find themselves overwhelmed by the huge amounts of information which may be associated with their interests. How to present the learning material (g.g. course learning objects) with respect to learning style is one of the key issues for recommender learning systems [3]. One approach to deal with this issue is to build the learner model, which is a core component in any intelligent or adaptive learning recommender system. The learner model represents many of the learner's features, such as knowledge and learning style, so as to be accessible for offering adaptation [4]. The learner must be set at the core of the instructional situation in order to encourage his/her integration into the learning process.

Adaptive learning uses techniques to interpret the activities of learners on the basis of domain-specific models, infers learner needs out of the interpreted activities, represents the needs in associated models appropriately, and acts upon adaptive learner profile in order to dynamically facilitate the learning process [5]. Actually, most courses tried to overcome onesize fits all approach. Adaptive learning systems can increase the individualisation of learners' learning [6] by changing content and delivery for a learner based on their learning profile as depicted in Figure 1. The learner profile includes

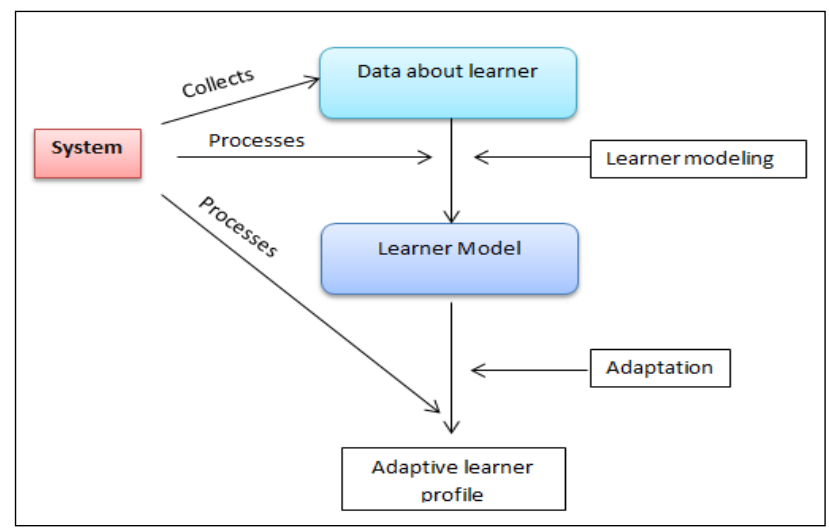

Fig. 1. Classic model of learner profile adaptation

several data such as personal information, knowledge and learning style. There are two main approaches to detect the learning styles: the explicit modelling (questionnaire based) and the implicit modelling (literature based).

The explicit modelling approach represents the learning characteristics and needs of each learners based on data obtained by requiring each learner to fill out a learning style questionnaire. Examples of systems that use this explicit modelling method are CS383 [55] INSPIRE [16] and iWeaver[51]. The implicit modelling approach means that an adaptive system continuously updates the learner model by monitoring interactions with the system; examples include Arthur system [10] and Protus 2.0 [56].

The proposed ULEARN recommender learning system 
combines the two approaches. The Felder-Silverman learning style questionnaire [35] is used to determine the initial learning style of the learner which is used together with the user preferences to initialise the learner profile. During the system usage, the learner profile is dynamically adapted based on the user behaviour (i.e. interactions with the system), knowledge and performance at learning. This paper focuses on the initialisation of the adaptive learner profile using a dynamic variant of the Felder-Silverman learning style questionnaire. The main contribution of this paper is threefold:

- An algorithm for constructing the adaptive learner profile during registration based on the Felder-Silverman learning style model (Sect. III)

- An empirical study to determine the order of questions for each of the four dimensions of the FelderSilverman learning style questionnaire (Sect. IV)

- An algorithm, built upon this ranking of questions, to calculate dynamically the initial learning style of the user as they go through the questionnaire (Sect. $\mathrm{V})$. The innovative feature of this algorithm is its ability to determine the learning style of the learner in each dimension from the users responses to just a few questions of the questionnaire; hence save the user time and effort from answering all the 44 questions of the Felder-Silverman learning style questionnaire.

\section{OVERVIEW OF THE FELDER-SILVERMAN LEARNING STYLE MODEL}

The learning style of the learner has been identified as an important factor that impacts the learning process. Learning style is the most significant parameter for personalization. Learners differ in the ways of perceiving, processing and receiving the information. Based on the means of processing and organizing the information, learners are considered to possess their own style of learning. Figure 2 shows the four dimensions of the Felder-Silverman learning style model (FSLSM) [35] which are related to the processing, understanding, input, and perception of information. Each of these dimensions is characterised by a pair X/Y (i.e. active/reflective, sequential/global, visual/verbal, and sensing/intuitive) meaning that the learning style of a learner in that dimension is $\mathrm{X}$ or $\mathrm{Y}$ to some extent. For example, in the information processing dimension the learning style of a user is active or reflective to some extent. In the information input dimension a user can be visual or verbal to some extent. FSLSM is considered the most stable and appropriate learning style model for adaptive hypermedia learning systems [50].

According to this description, the Index of Learning Styles (ILS) questionnaire proposes a list of 44 questions (see Table I) effective in identifying the style of each learner. There are 11 questions for each dimension and each question has two possible answers: the answer "a" or the answer "b". For a dimension characterised by the pair $\mathrm{X} / \mathrm{Y}$, the answer "a" corresponds to the preference for the learning style $\mathrm{X}$, while the answer "b" indicates the preference for the learning style Y.

To determine the learning style of the learner in a dimension using the questionnaire of Felder-Silverman, it is

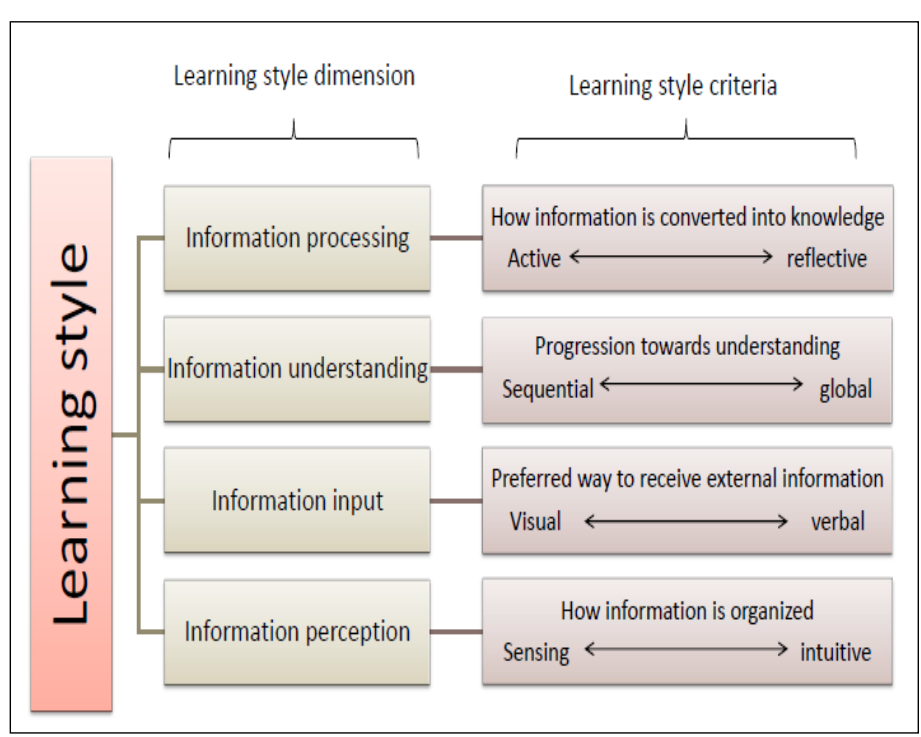

Fig. 2. FSLSM learning style model

sufficient to count the number of answers "a" and the number of answers "b" on the 11 questions corresponding to the dimension and calculate the difference between these two numbers. Obviously, this score is an odd number between 11 (all the answers of the learner are equal to "a") and -11 (all responses are equal to " $b$ "). A learner whose score is 1 or 3 ( -1 or -3 ) has a mild preference for $\mathrm{X}$ (resp. for $\mathrm{Y}$ ); yet is essentially well balanced to learn in a teaching environment that favours X or Y. For a score of 5 or 7 ( -5 or -7$)$, the learner has a moderate preference for $\mathrm{X}$ (resp. for $\mathrm{Y}$ ) and will learn more easily in a teaching environment that favours $X$ (resp. Y). Finally, a score of 9 or $11(-9$ or -11$)$ indicates a strong preference for $\mathrm{X}$ (resp. for $\mathrm{Y}$ ); and the learner may have real difficulty learning in an environment which does not support that preference.

\section{Algorithm for CReAting AN AdAptive LeARner PROFILE}

The proposed method for initialising the learner adaptive profile based on dynamic learning style questionnaire is illustrated by the block diagram in Figure 3 . The profile of the learner that includes the personal details of the learner is collected from the learner during the registration process. After the registration, student is asked to fill out ILS questionnaire described in the previous section. The algorithm includes the following basic steps:

- Step 1: (Registration) Student must register through ULEARN learning portal before using the system. During registration, personal data such as name, email address and password are collected.

- Step 2: (Fill out learning style questionnaire) After the registration step the student must take the ILS questionnaire. As the student answers the questionnaire, the system calculates dynamically the learning style of the student for each dimension by counting the number of answers "a" and the number of answers " $b$ ". When the number of "a" (or "b") reaches 7 (i.e. $60 \%$ of the 11 questions) in one dimension, the system skips the 


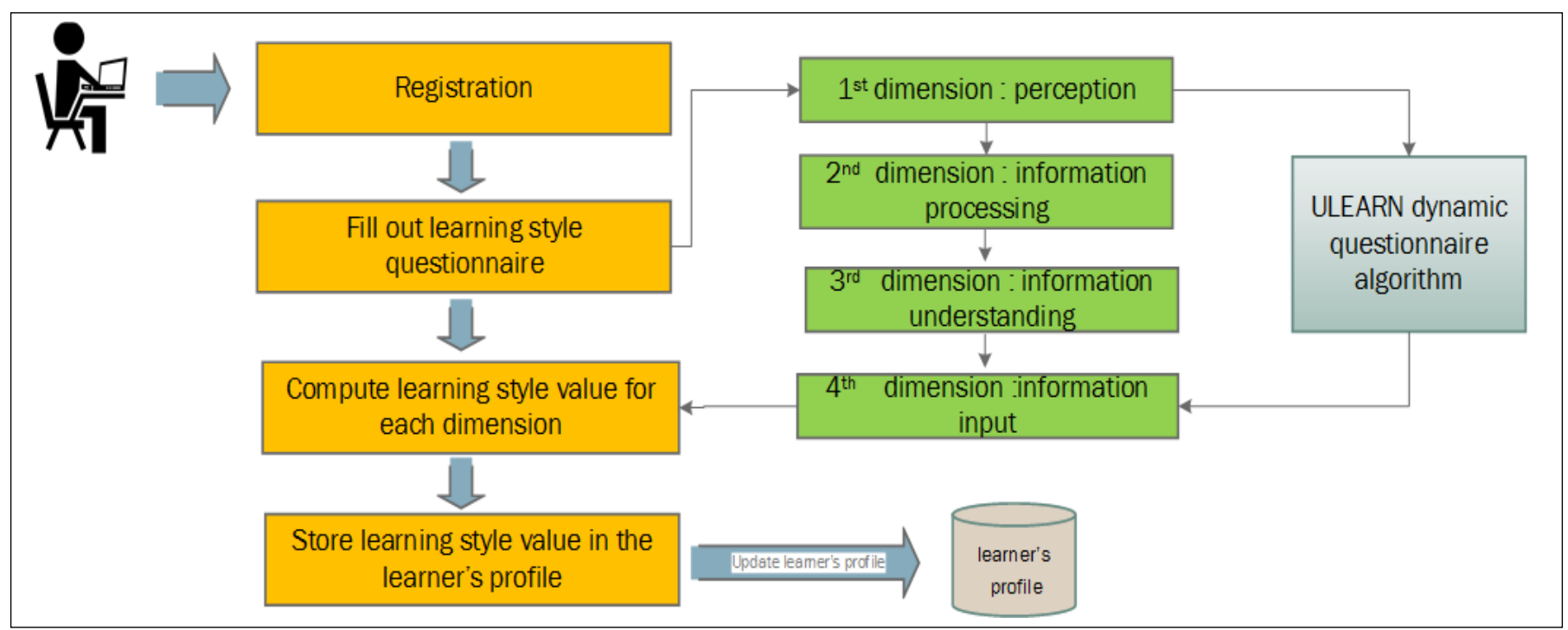

Fig. 3. Algorithm to create adaptive learner profile

rest of questions for that dimension and moves to the first question of the next dimension.

- $\quad$ Step 3: (Compute learning style value for each dimension) Calculate the learning style for each dimension as the percentages of "a" and "b". For example, in the dimension information input, one may have $60 \%$ visual and $40 \%$ verbal.

- Step 4: (Store learning style values in the student's profile) The initial learning style calculated through the ILS questionnaire is stored in the learner profile database.

\section{RANKING THE QUESTIONNAIRE QUESTIONS}

The ILS questionnaire has 44 questions; this may be too long for some learners and may lead to undesired behaviours such as skipping questions, answering falsely, or giving up the questionnaire (and the system) all together. Therefore the ULEARN learning system proposes a dynamic questionnaire algorithm which does not need to go through all the 44 questions of the questionnaire to determine the learning style of the learner. In order to do that, the ILS questionnaire is restructured into 4 groups of 11 questions, one for each dimension of the FSLSM. Within a dimension, questions are ranked based on how easy it is to choose between answer "a" and answer " $b$ ". The easiest questions in that respect will come first, and the difficult ones last.

A study was carried out to determine the ranking of questions in each dimension. Participants to the study were asked to tell for each question of the ILS questionnaire how easy it is to choose between answer "a" and answer "b" using a 5-levels Likert scale: 1. Very easy, 2. Easy, 3. Intermediate, 4. difficult, and 5. Very difficult. Thirty-four responses were received from which 30 were used for the analysis and the other 4 not included because they were incomplete. The score for each question were added up and normalised; and the results for each dimension are depicted in Fig.4-7. The most difficult questions are highlighted in red. Based on this study, questions can be ranked in ascending order of difficulty levels in each dimension as shown in Table I. This ranking of questions is used as precondition for the algorithm to calculate a learner's initial learning style using the ILS questionnaire, presented in the following section.

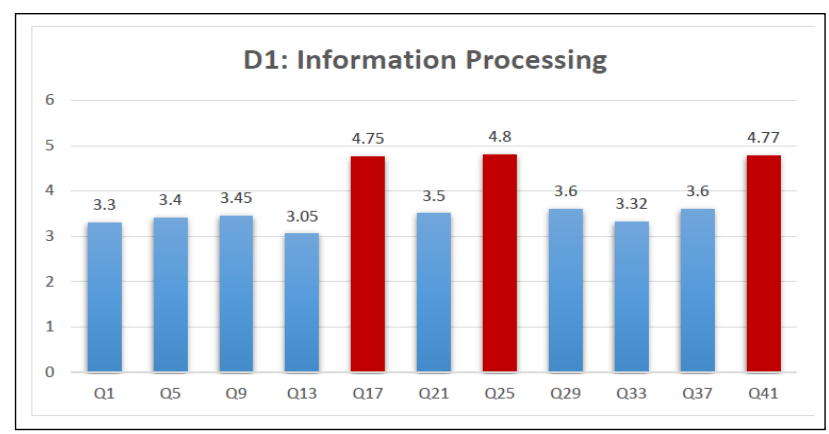

Fig. 4. Difficulty level of questions in Information Processing

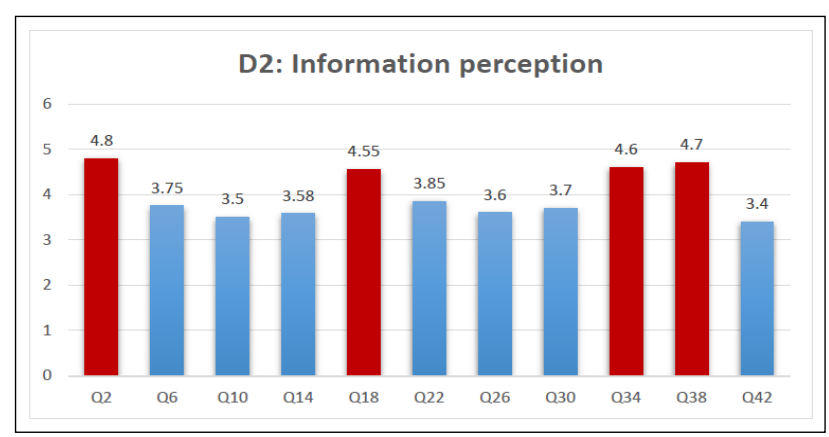

Fig. 5. Difficulty level of questions in Information Perception

\section{Algorithm For CAlculating Initial LEARNing STYLE}

The algorithm Initial_LS described by the pseudocode in Fig. 8 and the flowchart in Fig. 9 calculates the initial learning style of a learner using the ILS questionnaire given in Table I. The algorithm counts the number of answers " $a$ " and 
TABLE I. ORDER OF QUESTIONS IN EACH DIMENSION

\begin{tabular}{|c|c|c|c|}
\hline \multicolumn{4}{|l|}{ D1: Information Processing } \\
\hline Question & FSLSM question's Sequence & ULEARN Sequence & Difficulty level \\
\hline $\begin{array}{l}\text { In classes I have taken a) I have usually gotten to know many of the students. } \\
\text { b) I have rarely gotten to know many of the students. }\end{array}$ & $T_{1}$ & ${ }_{1}$ & 3.05 \\
\hline I understand something better after I a) try it out. b) think it through. & 1 & 2 & 3.3 \\
\hline $\begin{array}{l}\text { When I have to work on a group project, I first want to a) have group brainstorming } \\
\text { where everyone contributes ideas.b) brainstorm individually and then come together } \\
\text { as a group to compare ideas. }\end{array}$ & 33 & 3 & 3.32 \\
\hline $\begin{array}{l}\text { When I am learning something new, it helps me toa) talk about it. } \\
\text { b) think about it. }\end{array}$ & 5 & 4 & 3.4 \\
\hline $\begin{array}{l}\text { In a study group working on difficult material, I am more likely to } \\
\text { a) jump in and contribute ideas.b) sit back and listen. }\end{array}$ & 9 & 5 & 3.45 \\
\hline I prefer to study a) in a study group.b) alone. & 21 & 6 & 3.5 \\
\hline I more easily remember a) something I have done. b) something I have thought a lot about. & 29 & 7 & 3.6 \\
\hline I am more likely to be considered a) outgoing. b) reserved. & 37 & 8 & 3.6 \\
\hline $\begin{array}{l}\text { When I start a homework problem, I am more likely to a) start working on the solution } \\
\text { immediately.b) try to fully understand the problem first. }\end{array}$ & 17 & 9 & 4.75 \\
\hline $\begin{array}{l}\text { The idea of doing homework in groups, with one grade for the entire group, a) appeals to me. } \\
\text { b) does not appeal to me. }\end{array}$ & 41 & 10 & 4.77 \\
\hline I would rather first a) try things out. b) think about how Im going to do it. & 25 & 11 & 4.8 \\
\hline \multicolumn{4}{|l|}{ D2: Information Perception } \\
\hline $\begin{array}{l}\text { When I am doing long calculations, a) I tend to repeat all my steps and } \\
\text { check my work carefully. b) I find checking my work tiresome } \\
\text { and have to force myself to do it. }\end{array}$ & 42 & 1 & 3.4 \\
\hline I find it easier a) to learn facts. b) to learn concepts. & 10 & 2 & 3.5 \\
\hline $\begin{array}{l}\text { In reading nonfiction, I prefer } \\
\text { a) something that teaches me new facts or tells me } \\
\text { how to do something.b) something that gives me new ideas to think about. }\end{array}$ & 14 & 3 & 3.58 \\
\hline $\begin{array}{l}\text { When I am reading for enjoyment, I like writers to a) clearly say what they mean. } \\
\text { b) say things in creative, interesting ways. }\end{array}$ & 26 & 4 & 3.6 \\
\hline $\begin{array}{l}\text { When I have to perform a task, I prefer to a) master one way of doing it. } \\
\text { b) come up with new ways of doing it. }\end{array}$ & 30 & 5 & 3.7 \\
\hline $\begin{array}{l}\text { If I were a teacher, I would rather teach a course a) that deals with facts and real life situations. } \\
\text { b) that deals with ideas and theories. }\end{array}$ & 6 & 6 & 3.75 \\
\hline $\begin{array}{l}\text { I am more likely to be considered a) careful about the details of my work. } \\
\text { b) creative about how to do my work. }\end{array}$ & 22 & 7 & 3.85 \\
\hline I prefer the idea of a) certainty. b) theory. & 18 & 8 & 4.55 \\
\hline I consider it higher praise to call someone a) sensible. b) imaginative. & 34 & 9 & 4.6 \\
\hline I prefer courses that emphasize a) concrete material (facts, data). b) abstract material (concepts, theories). & 38 & 10 & 4.7 \\
\hline I would rather be considered a) realistic. b) innovative. & 2 & 11 & 4.8 \\
\hline \multicolumn{4}{|l|}{$\begin{array}{ll} & \text { D3: Information Input }\end{array}$} \\
\hline $\begin{array}{l}\text { When I am learning a new subject, I prefer to a) stay focused on that subject, learning as much } \\
\text { about it as I can. b) try to make connections between that subject and related subjects }\end{array}$ & 36 & 1 & 3.4 \\
\hline $\begin{array}{l}\text { I tend to a) understand details of a subject but may be fuzzy about its overall structure. } \\
\text { b) understand the overall structure but may be fuzzy about details. }\end{array}$ & 4 & 2 & 3.45 \\
\hline $\begin{array}{l}\text { It is more important to me that an instructor a) lay out the material in clear sequential steps. } \\
\text { b) give me an overall picture and relate the material to other subjects. }\end{array}$ & 20 & 3 & 3.45 \\
\hline $\begin{array}{l}\text { When solving problems in a group, I would be more likely to a) think of the steps in the solution process. } \\
\text { b) think of possible consequences or applications of the solution in a wide range of area }\end{array}$ & 44 & 4 & 3.55 \\
\hline $\begin{array}{l}\text { When considering a body of information, I am more likely to a) focus on details and miss the big picture. } \\
\text { b) try to understand the big picture before getting into the details }\end{array}$ & 28 & 5 & 3.6 \\
\hline $\begin{array}{l}\text { Some teachers start their lectures with an outline of what they will cover. Such outlines are } \\
\text { a) somewhat helpful to me. b) very helpful to me. }\end{array}$ & 40 & 6 & 3.6 \\
\hline $\begin{array}{l}\text { When I am analyzing a story or a novel a) I think of the incidents and try to put them together to figure } \\
\text { out the themes. b) I just know what the themes are when,I finish reading and then } \\
\text { I have to go back and find the incidents that demonstrate them. }\end{array}$ & 16 & 7 & 3.65 \\
\hline $\begin{array}{l}\text { When I solve math problems a) I usually work my way to the solutions one step at a time. } \\
\text { b) I often just see the solutions but then have to struggle to figure out the steps to get to them. }\end{array}$ & 12 & 8 & 3.75 \\
\hline $\begin{array}{l}\text { I learn a) at a fairly regular pace. If I study hard, Ill get it. b) in fits and starts., } \\
\text { Ill be totally confused and then suddenly it all clicks. }\end{array}$ & 24 & 9 & 4.5 \\
\hline $\begin{array}{l}\text { When writing a paper, I am more likely to a) work on (think about or write) the beginning of } \\
\text { the paper and progress forward. b) work on (think about or write) different parts } \\
\text { of the paper and then order them. }\end{array}$ & 32 & 10 & 4.65 \\
\hline $\begin{array}{l}\text { Once I understand a) all the parts, I understand the whole thing. b) the whole thing, } \\
\text { I see how the parts fit. }\end{array}$ & 8 & 11 & 4.7 \\
\hline \multicolumn{4}{|l|}{\begin{tabular}{|ll} 
& D4: Information Understanding
\end{tabular}} \\
\hline When I think about what I did yesterday, I am most likely to get a) a picture. b) words & 3 & 1 & 3.15 \\
\hline $\begin{array}{l}\text { When I meet people at a party, I am more likely to remember a) what they looked like. } \\
\text { b) what they said about themselves }\end{array}$ & 35 & 2 & 3.2 \\
\hline $\begin{array}{l}\text { When I see a diagram or sketch in class, I am most likely to remember a) the picture. } \\
\text { b) what the instructor said about it. }\end{array}$ & 27 & 3 & 3.3 \\
\hline $\begin{array}{l}\text { I prefer to get new information in a) pictures, diagrams, graphs, or maps. } \\
\text { b) written directions or verbal information. }\end{array}$ & 7 & 4 & 3.5 \\
\hline When I get directions to a new place, I prefer a) a map. b) written instructions & 23 & 5 & 3.6 \\
\hline $\begin{array}{l}\text { In a book with lots of pictures and charts, I am likely to a) look over the pictures and } \\
\text { charts carefully. b) focus on the written text. }\end{array}$ & 11 & 6 & 3.7 \\
\hline I remember best a) what I see. b) what I hear. & 19 & 7 & 3.75 \\
\hline $\begin{array}{l}\text { I tend to picture places I have been a) easily and fairly accurately. } \\
\text { b) with difficulty and without much detail. }\end{array}$ & 43 & 8 & 4.5 \\
\hline I like teachers a) who put a lot of diagrams on the board. b) who spend a lot of time explaining. & 15 & 9 & 4.65 \\
\hline When someone is showing me data, I prefer a) charts or graphs. b) text summarizing the results & 31 & 10 & 4.8 \\
\hline For entertainment, I would rather a) watch television. b) read a book. & 39 & 11 & 4.85 \\
\hline
\end{tabular}

IEEE 


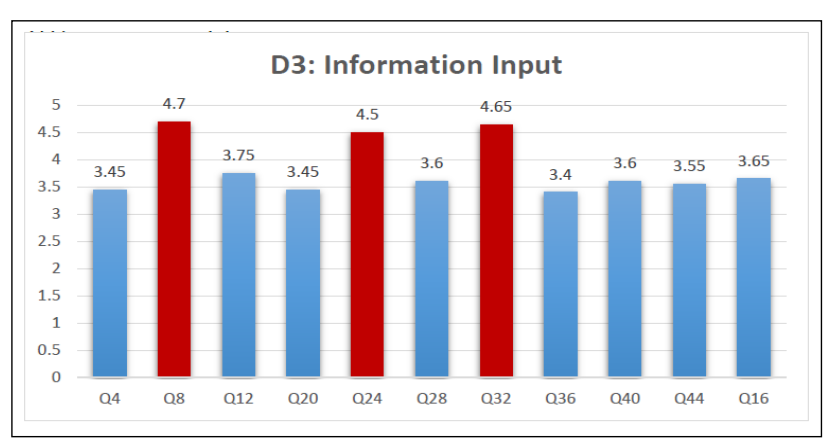

Fig. 6. Difficulty level of questions in Information Input

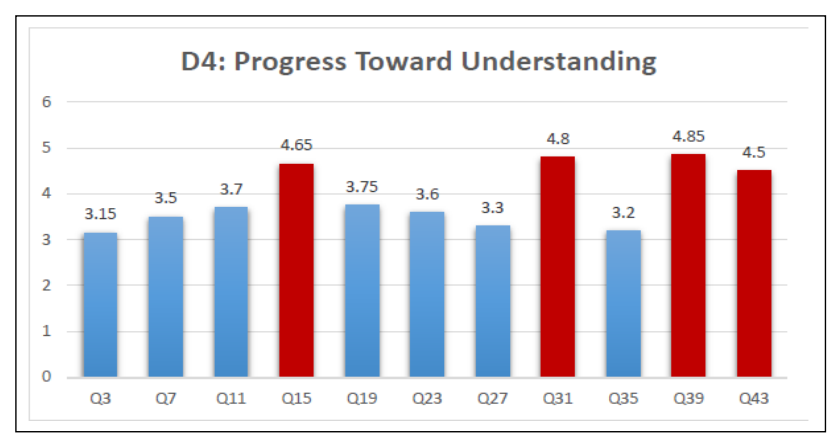

Fig. 7. Difficulty level of questions in Information Understanding

the number of answers " $\mathrm{b}$ " in each dimension. If the number of answers "a" or the number of answers "b" reaches 7, the rest of questions in that dimension will be skipped. In this way, only learners with mild preferences will take all the 11 questions of the dimension. This is based on the assumption that if $60 \%$ of a learner's answers are in favour of one preference ( $\mathrm{X}$ or $\mathrm{Y}$ ) in a dimension, then that learner will likely be fine in a teaching environment that favours that preference. However, this threshold of $60 \%$ may be revised for some courses as appropriate during the validation of the system in real-word settings.

In the flowchart in Fig. 9, the variable $i$ ranges over the 4 dimensions of the FSLSM and the variable $j$ refers to the current question being processed within a dimension. Thus, $j$ ranges over the 11 questions of a dimension. The number of answers "a" (answers "b") in the dimension $i$ is calculated in the variable $A_{i}\left(\right.$ resp. $\left.B_{i}\right)$, for $1 \leq i \leq 4$. The algorithm ends when all the 4 dimensions have been processed. To illustrate how this algorithm works, Table II shows the execution outputs for 5 different learners who have taken the ILS questionnaire. The notation \#a means the number of answer "a". The learner Clara, in each dimension chooses the same answer for the first 7 questions. She demonstrates the best case scenario where the smallest (28) number of questions are taken.

Fatima and Bob represent the worst case scenarios where all the 44 questions are taken; these are the only situations where this happens. For Fatima the difference \#a - \#b in each dimension is either 1 or -1 , while that difference is either 3 or -3 for Bob. They both have mild learning style preferences (see Sect. II) in each dimension and so are well balanced to learn in any teaching environment. The other learners learning styles are moderate at least.

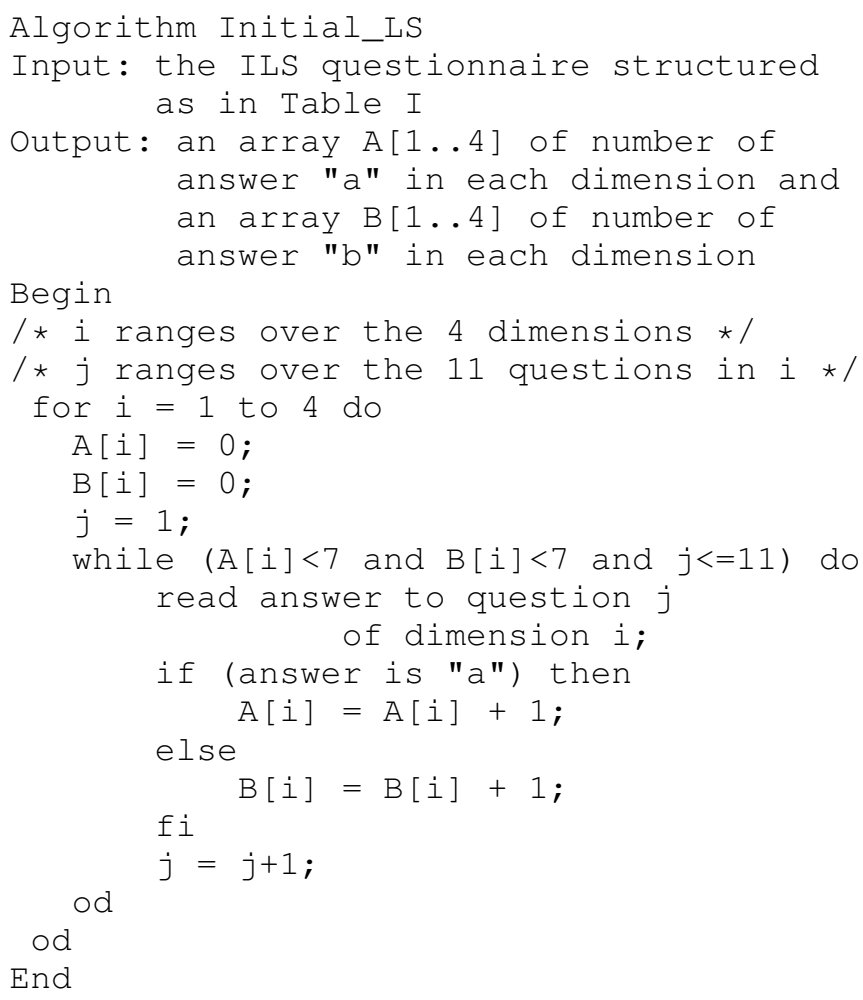

Fig. 8. Pseudo-code of the algorithm for calculating initial learning style

TABLE II. EXAMPLES OF EXECUTION OUTPUT OF THE ALGORITHM INITIAL_LS

\begin{tabular}{|c|c|c|c|c|c|c|c|c|c|}
\hline & \multicolumn{8}{|c|}{ Learning Style Dimensions } & \multirow[b]{3}{*}{ Total } \\
\hline & \multicolumn{2}{|c|}{ Processing } & \multicolumn{2}{|c|}{ Perception } & \multicolumn{2}{|c|}{ Input } & \multicolumn{2}{|c|}{ Understanding } & \\
\hline & $\# \mathrm{a}$ & \#b & $\# \mathrm{a}$ & $\# \mathrm{~b}$ & $\mathrm{\# a}$ & \#b & $\# \mathrm{a}$ & $\# \mathrm{~b}$ & \\
\hline Tom & 2 & 7 & 1 & 7 & 7 & 3 & 0 & 7 & 34 \\
\hline Clara & 0 & 7 & 7 & 0 & 0 & 7 & 0 & 7 & 28 \\
\hline Fatima & 5 & 6 & 6 & 5 & 5 & 6 & 6 & 5 & 44 \\
\hline Bob & 7 & 4 & 4 & 7 & 4 & 7 & 7 & 4 & 44 \\
\hline Alice & 1 & 7 & 1 & 7 & 7 & 0 & 0 & 7 & 30 \\
\hline
\end{tabular}

\section{IMPLEMENTATION}

Our proposed framework ULEARN is an adaptive learning management system to provide adaptive course content based on personalised student profile. ULEARN has been implemented in java and SQL sever. The main purpose of system is to recommend useful and personalised materials prepared based on learner preferences in e-learning context. ULEARN supports three main roles:

1) Learners: attend courses and use the system in order to gain certain knowledge.

2) instructors: add course lessons and learning objects in different format as well as assignments.

3) administrator: assigns learners and instructors to specific courses and manages system database.

Hence, the system provides separate user interfaces for these roles. Instructor's interface helps managing data about learners and course materials. The work-through of the learner interface is given in Fig. 10. An existing user logs in the system by entering a valid username and password as shown in Fig. 11. A new user needs to register with the system and will be 


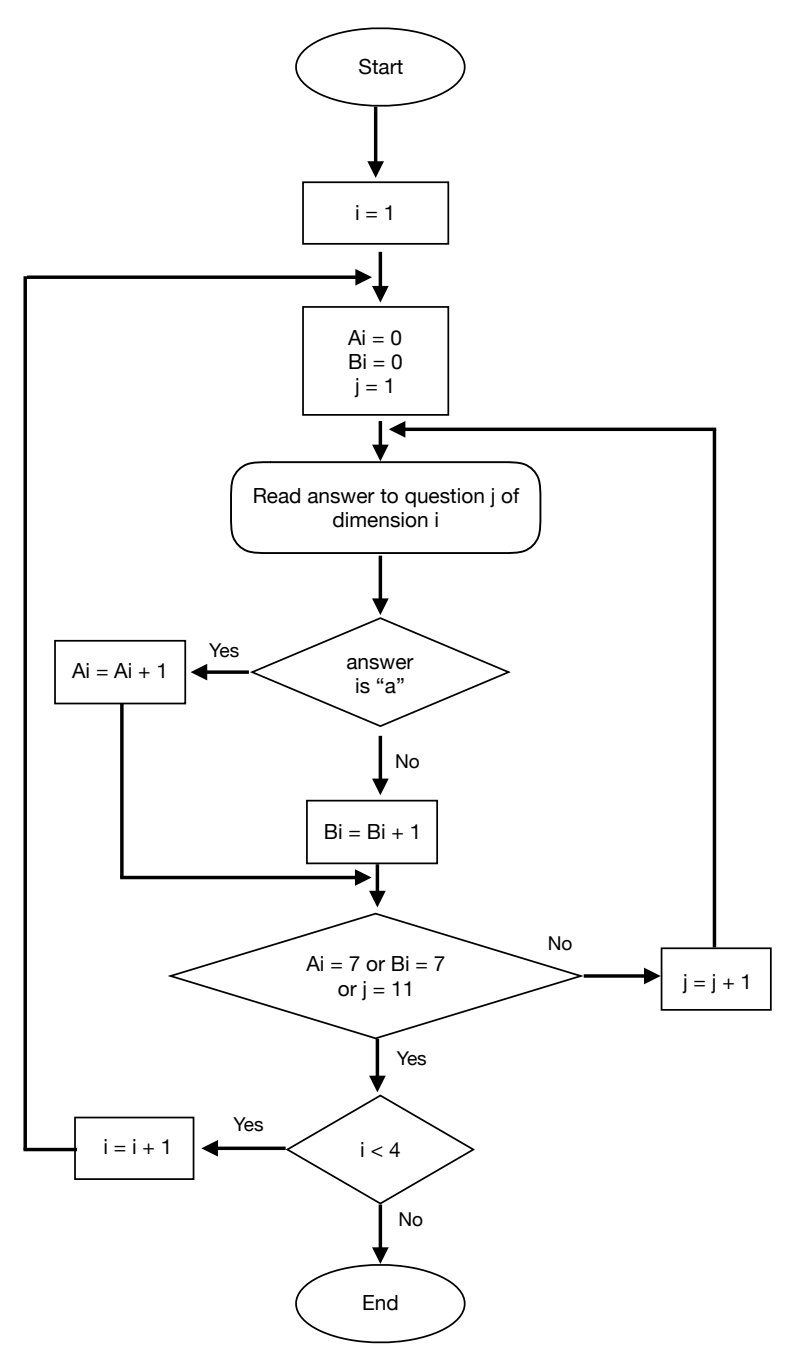

Fig. 9. Flowchart of the algorithm for calculating initial learning style

required to enter personal information as depicted in Fig. 12; and then answer the ILS questionnaire as explained above. The questionnaire interface looks like in Fig. 13.

\section{RELATED WORK}

This section presents a review of the existing literature relevant to this study with a focus on a brief overview of common techniques used to adapt personalized learner profile and previous related review studies. Table III presents a comparative study between the most known personalised elearning systems. In addition, we give some examples of elearning systems that implement these methods for modelling the learner's individual differences and highlight their limitations.

\section{CONCLUSION}

Personalised learner profile has emerged as core area in adaptive e-learning applications in which each learner's interests, preferences and contextual information were studied precisely. Characteristics of learning style play crucial role in identifying their learning style preferences. It helps to provide adaptive learning experiences in personalisation of learning materials based on the interactions with the learners. This paper proposes an algorithm for constructing the adaptive learner profile during registration based on the FelderSilverman learning style model. An empirical study was undertaken to determine the order of questions for each of the four dimensions of the Felder-Silverman learning style questionnaire. This ranking of questions was used to build an algorithm that calculates dynamically the initial learning style of the user as they go through the questionnaire. This algorithm can infer the learning style of the learner in each dimension from the users responses to just a few questions of the questionnaire; hence save the user time and effort from answering all the 44 questions of the Felder-Silverman learning style questionnaire. In future work, an adaptive engine will be developed to adapt the user profile based on the learner behaviour, knowledge and performances.

\section{REFERENCES}

[1] Ricci, Francesco. "Context-aware music recommender systems: workshop keynote abstract." Proceedings of the 21st International Conference on World Wide Web. ACM, 2012.

[2] Gorgoglione, Michele, Cosimo Palmisano, and Alexander Tuzhilin. "Personalization in context: Does context matter when building personalized customer models?.” Data Mining, 2006. ICDM'06. Sixth International Conference on. IEEE, 2006.

[3] Lo, Jia-Jiunn, Ya-Chen Chan, and Shiou-Wen Yeh. "Designing an adaptive web-based learning system based on students cognitive styles identified online." Computers and Education 58.1 (2012): 209-222.

[4] Brusilovsky, Peter, and Eva Milln. "User models for adaptive hypermedia and adaptive educational systems." The adaptive web. Springer Berlin Heidelberg, 2007. 3-53.

[5] Paramythis, Alexandros, and Susanne Loidl-Reisinger. "Adaptive learning environments and e-learning standards." Second european conference on e-learning. Vol. 1. No. 2003. 2003.

[6] Bostwick, Keiko, and Kathryn Becker-Blease. "Adaptive Quizzing Associated with an Increase in Overall Learning." (2014).

[7] Carver, Curtis A., Richard A. Howard, and William D. Lane. "Enhancing student learning through hypermedia courseware and incorporation of student learning styles." IEEE transactions on Education 42.1 (1999): 33-38.

[8] Papanikolaou, Kyparisia A., et al. "Personalizing the Interaction in a Web-based Educational Hypermedia System: the case of INSPIRE." User modeling and user-adapted interaction 13.3 (2003): 213-267.

[9] Wolf, Christian. 'iWeaver: towards' learning style'-based e-learning in computer science education." Proceedings of the fifth Australasian conference on Computing education-Volume 20. Australian Computer Society, Inc., 2003.

[10] Gilbert, Juan E., and Chia Y. Han. "Arthur: Adapting Instruction To Accommodate Learning Style." (1999).

[11] Klanja-Milievi, Aleksandra, et al. "E-Learning personalization based on hybrid recommendation strategy and learning style identification." Computers and Education 56.3 (2011): 885-899.

[12] Manouselis, Nikos, et al. "Recommender systems in technology enhanced learning." Recommender systems handbook (2011): 387-415.

[13] Cazella, Silvio Csar, et al. "Developing a Learning Objects Recommender System Based on Competences to Education: Experience Report." New Perspectives in Information Systems and Technologies, Volume 2. Springer, Cham, 2014. 217-226.

[14] Zaina, Luciana AM, Jose F. Rodrigues Jr, and Graa Bressan. "An approach to design the student interaction based on the recommendation of e-learning objects." Proceedings of the 28th ACM International Conference on Design of Communication. ACM, 2010. 


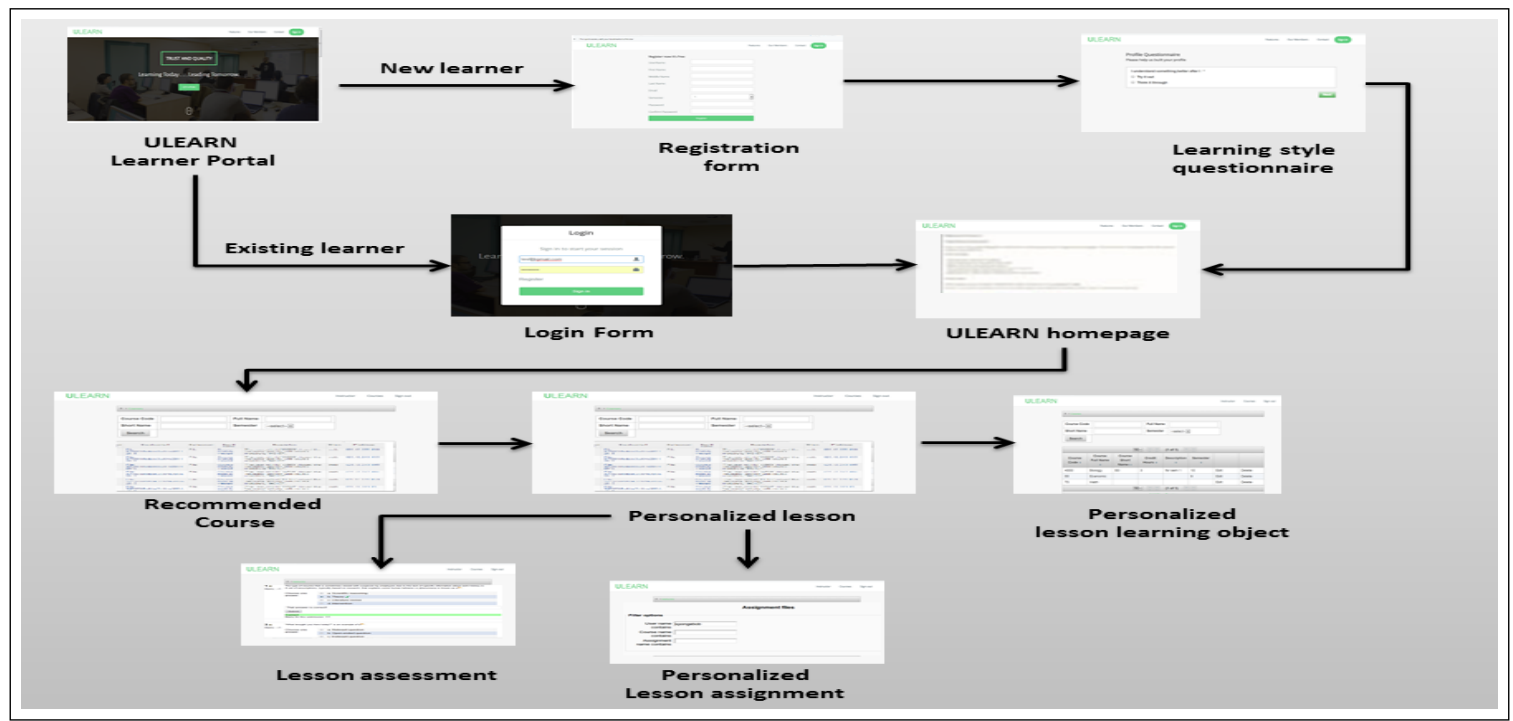

Fig. 10. ULEARN interface map

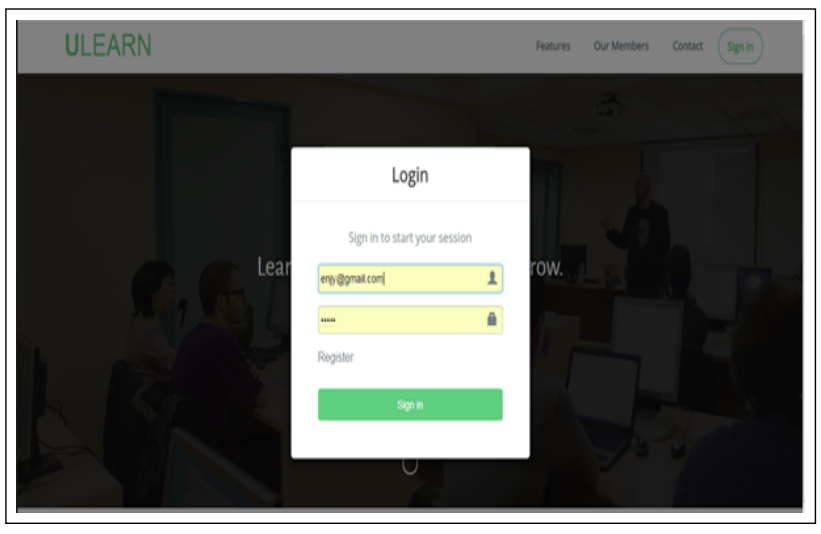

Fig. 11. Student login page

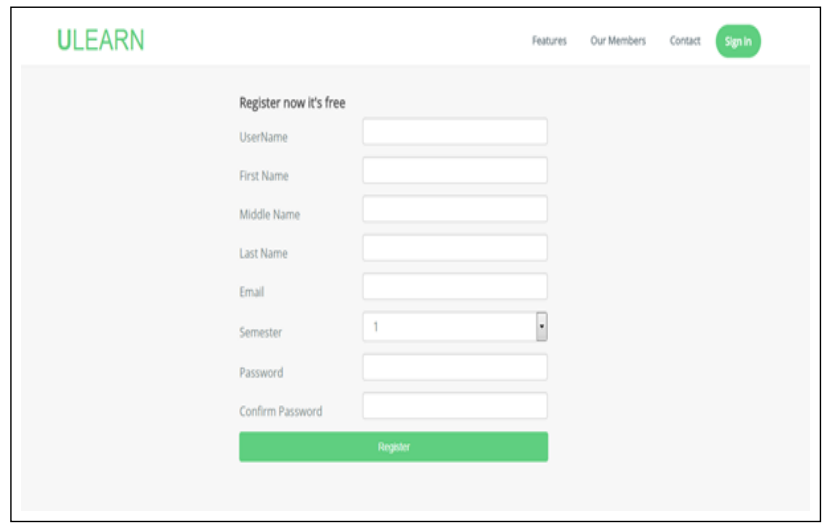

Fig. 12. Registration page

[15] Kay, Judy. "Learner control." User modeling and user-adapted interaction 11.1 (2001): 111-127.

[16] Papanikolaou, Kyparisia A., et al. "Personalizing the Interaction in a Web-based Educational Hypermedia System: the case of INSPIRE." User modeling and user-adapted interaction 13.3 (2003): 213-267.

[17] Ricci, Francesco. "Context-aware music recommender systems: workshop keynote abstract." Proceedings of the 21st International Conference on World Wide Web. ACM, 2012.

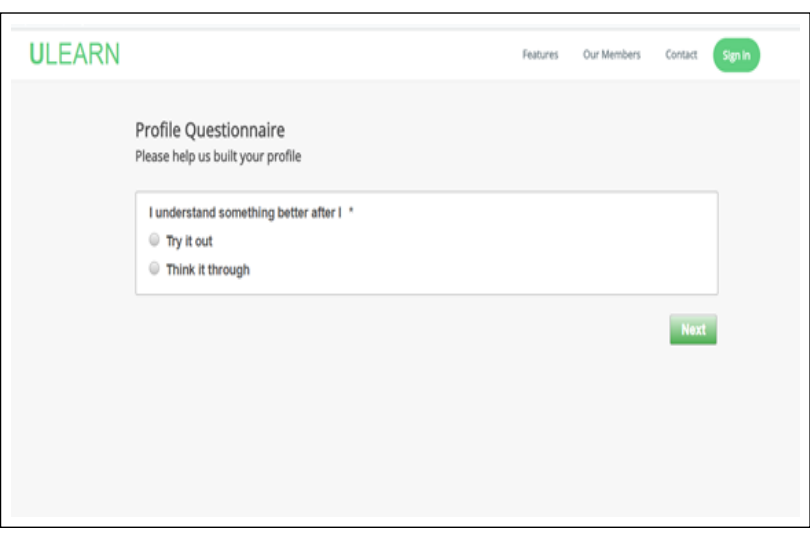

Fig. 13. Questionnaire interface

[18] Blanco-Fernndez, Yolanda, Martn Lpez-Nores, and Jos J. Pazos-Arias. "Adapting spreading activation techniques towards a new approach to content-based recommender systems." Intelligent Interactive Multimedia Systems and Services (2010): 1-11.

[19] Gorgoglione, Michele, Cosimo Palmisano, and Alexander Tuzhilin. "Personalization in context: Does context matter when building personalized customer models?.” Data Mining, 2006. ICDM'06. Sixth International Conference on. IEEE, 2006.

[20] Stiubiener, Itana, Wilson Vicente Ruggiero, and Marta Costa Rosatelli. "An approach to personalisation in e-learning." Advanced Learning Technologies, 2007. ICALT 2007. Seventh IEEE International Conference on. IEEE, 2007.

[21] Takcs, Ondej, Jana armanov, and Kateina Kostolnyov. "Analysis of learning styles for adaptive E-learning." Digital Information Processing and Communications. Springer, Berlin, Heidelberg, 2011. 368-376.

[22] Essaid El Bachari, El Hassan Abelwahed, and Mohammed El Adnani. "E-LEARNING PERSONALIZATION BASED ON DYNAMIC LEARNERSPREFERENCE." (2011).

[23] Dora, Fabiano A., et al. "Comparing strategies for modeling students learning styles through reinforcement learning in adaptive and intelligent educational systems: An experimental analysis." Expert Systems with Applications 40.6 (2013): 2092-2101.

[24] Redmond, James A., Cathal Walsh, and Adrian Parkinson. "Equilibriating instructional media for cognitive styles." ACM SIGCSE Bulletin. Vol. 35. No. 3. ACM, 2003.

[25] Miller, L. Michele. "Using learning styles to evaluate computer-based 
TABLE III. SyStEMS AdAPTATION AND USER MODELLING

\begin{tabular}{|c|c|c|c|c|c|c|}
\hline System & $\begin{array}{l}\text { Web } \\
\text { based }\end{array}$ & Description & $\begin{array}{l}\text { learning style } \\
\text { model }\end{array}$ & $\begin{array}{l}\text { Data } \\
\text { Source }\end{array}$ & $\begin{array}{c}\text { dynamic } \\
\text { user } \\
\text { modeling }\end{array}$ & limitations \\
\hline [53] & yes & $\begin{array}{l}\text { The system can categorise } \\
\text { students according to FSLSM } \\
\text { dimensions through case } \\
\text { based reasoning inference. }\end{array}$ & FSLSM & $\begin{array}{l}\text { questionnaire, } \\
\text { student } \\
\text { behaviour }\end{array}$ & No & $\begin{array}{l}\text { system recommendation } \\
\text { based on static user profile. } \\
\text { That is the reason why highly } \\
\text { personalized recommendation } \\
\text { cannot achieve }\end{array}$ \\
\hline [46] & Yes & $\begin{array}{l}\text { system adapts Chapter, } \\
\text { sections, } \\
\text { sub-sections, and } \\
\text { learning objects }\end{array}$ & $\begin{array}{l}\text { Unified Learning } \\
\text { Style Model }\end{array}$ & $\begin{array}{l}\text { Student } \\
\text { behaviour }\end{array}$ & Yes & $\begin{array}{l}\text { could be extended by adding } \\
\text { variety of adaptation actions, } \\
\text { collaboration level adaptation }\end{array}$ \\
\hline [52] & Yes & $\begin{array}{l}\text { system generates teaching } \\
\text { tasks and teaching rules }\end{array}$ & $\begin{array}{l}\text { FSLSM } \\
\text { understanding } \\
\text { and perception }\end{array}$ & questionnaire & No & $\begin{array}{l}\text { system adaptation rules } \\
\text { defined by a teacher } \\
\text { which decrease } \\
\text { the recommendation } \\
\text { accuracy }\end{array}$ \\
\hline [44] & - & $\begin{array}{l}\text { system generates learning } \\
\text { resource ordering } \\
\text { according entry dimension }\end{array}$ & FSLSM & questionnaire & No & $\begin{array}{l}\text { recommendation } \\
\text { based on static } \\
\text { user profile. }\end{array}$ \\
\hline [54] & Yes & $\begin{array}{l}\text { The system generates } \\
\text { Course, unit, topics } \\
\text { and reading materials }\end{array}$ & $\begin{array}{l}\text { perception, } \\
\text { processing and } \\
\text { understanding }\end{array}$ & questionnaire behaviour & Yes & $\begin{array}{l}\text { the system cannot distinguish } \\
\text { between visual and verbal learners } \\
\text { also it cannot provide } \\
\text { them assistance accordingly. }\end{array}$ \\
\hline [51] & Yes & $\begin{array}{l}\text { the system adapt learning } \\
\text { strategies which generate } \\
\text { media experiences }\end{array}$ & $\begin{array}{l}\text { Dunn \& Dunn } \\
\text { Model }\end{array}$ & questionnaire & No & $\begin{array}{l}\text { the course recommendation based on static } \\
\text { student profile.Bayesian Networks can } \\
\text { enhance by the combination of } \\
\text { content-based and collaborative approaches }\end{array}$ \\
\hline$[56]$ & Yes & $\begin{array}{l}\text { system adapt course, Topics, } \\
\text { lessons, and educational } \\
\text { materials }\end{array}$ & FSLSM & $\begin{array}{l}\text { questionnaire } \\
\text { behaviour }\end{array}$ & Yes & $\begin{array}{l}\text { the system is used for learning Java } \\
\text { programming language only } \\
\text { I do recommend if it can be used } \\
\text { in other domains }\end{array}$ \\
\hline [48] & Yes & $\begin{array}{l}\text { Adapt teaching activates based on } \\
\text { knowledge and learning abilities. }\end{array}$ & & behaviour & Yes & $\begin{array}{l}\text { the system should be extended with an } \\
\text { adaptive mechanism that will monitor } \\
\text { the student during the interaction, and } \\
\text { adapt the level of feedback automatically }\end{array}$ \\
\hline
\end{tabular}

instruction." Computers in human behavior 21.2 (2005): 287-306.

[26] Klanja-Milievi, Aleksandra, et al. "E-Learning personalization based on hybrid recommendation strategy and learning style identification." Computers and Education 56.3 (2011): 885-899.

[27] Sugiyama, Kazunari, Kenji Hatano, and Masatoshi Yoshikawa. "Adaptive web search based on user profile constructed without any effort from users." Proceedings of the 13th international conference on World Wide Web. ACM, 2004.

[28] Velzquez, Ana Lidia Franzoni. A proposed method for adapting and integrating student learning style, teaching strategies and electronic media. Diss. Institut National des Tlcommunications, 2009.

[29] C. Mulwa, S. Lawless, M. Sharp, I. Arnedillo-Sanchez, V. Wade, Adaptive educational hypermedia systems in technology enhanced learning: a literature review, in: Proceedings of the $2010 \mathrm{ACM}$ conference on Information technology education, ACM, 2010, pp. 7384.

[30] Neven, Filip, and Erik Duval. "Reusable learning objects: a survey of LOM-based repositories." Proceedings of the tenth ACM international conference on Multimedia. ACM, 2002.

[31] Balatsoukas, Panos, Anne Morris, and Ann O'Brien. "Learning objects update: Review and critical approach to content aggregation." Journal of Educational Technology and Society 11.2 (2008).

[32] Neven, Filip, and Erik Duval. "Reusable learning objects: a survey of LOM-based repositories." Proceedings of the tenth ACM international conference on Multimedia. ACM, 2002.

[33] Richards, Jack C., and Theodore S. Rodgers. Approaches and methods in language teaching. Cambridge university press, 2014.

[34] Gredler, Margaret E. "Games and simulations and their relationships to learning." Handbook of research on educational communications and technology 2 (2004): 571-581.

[35] Felder, Richard M., and Silverman, Linda K. "Learning and teaching styles in engineering education." Engineering education 78.7 (1988): 674681.

[36] Jeffries, Pamela R. "A framework for designing, implementing, and evaluating: Simulations used as teaching strategies in nursing." Nursing education perspectives 26.2 (2005): 96-103.
[37] Silberman, Mel. Active Learning: 101 Strategies To Teach Any Subject. Prentice-Hall, PO Box 11071, Des Moines, IA 50336-1071, 1996.

[38] Graham, Steve, and Karen Harris. Writing Better: Effective Strategies for Teaching Students with Learning Difficulties. Brookes Publishing Company. PO Box 10624, Baltimore, MD 21285, 2005.

[39] Mills, Julie E., and David F. Treagust. "Engineering educationIs problem-based or project-based learning the answer." Australasian journal of engineering education 3.2 (2003): 2-16.

[40] Lawless, Kimberly A., and James W. Pellegrino. "Professional development in integrating technology into teaching and learning: Knowns, unknowns, and ways to pursue better questions and answers." Review of educational research 77.4 (2007): 575-614.

[41] Dutson, Alan J., et al. "A Review of Literature on Teaching Engineering Design Through ProjectOriented Capstone Courses." Journal of Engineering Education 86.1 (1997): 17-28.

[42] Cui, Jiali, et al. "A fast and robust iris localization method based on texture segmentation." Proceedings of SPIE. Vol. 5404. 2004.

[43] He, Z., Tan, T., Sun, Z., Qiu, X.: Robust eyelid eyelash and shadow localization for iris recognition. In: 15th IEEE International Conference on Image Processing, pp. 265268 (2008)

[44] Baldiris, Silvia, et al. "Adaptation Decisions and Profiles Exchange among Open Learning Management Systems Based on Agent Negotiations and Machine Learning Techniques." International Conference on Human-Computer Interaction. Springer Berlin Heidelberg, 2009.

[45] Mitrovic, Antonija. "An intelligent SQL tutor on the web." International Journal of Artificial Intelligence in Education 13.2-4 (2003): 173-197.

[46] Popescu, Elvira, Costin Badica, and Lucian Moraret. "Accommodating learning styles in an adaptive educational system." Informatica 34.4 (2010).

[47] Gilbert, Juan E., and Chia Y. Han. "Arthur: Adapting Instruction To Accommodate Learning Style." (1999).

[48] Mitrovic, Antonija, Brent Martin, and Michael Mayo. "Using evaluation to shape ITS design: Results and experiences with SQL-Tutor." User Modeling and User-Adapted Interaction 12.2 (2002): 243-279.

[49] Riad, A. M., Hamdy K. El-Minir, and H. A. El-Ghareeb. "Review of elearning systems convergence from traditional systems to services based 
adaptive and intelligent systems.” Journal of Convergence Information Technology 4.2 (2009): 108-131.

[50] Silva, Daydson Hugo, and Fabiano Azevedo Dora. "An Automatic Approach for Customization of Teaching Process Based on Learning Styles in Adaptive and Intelligent Learning Systems.” Brazilian Journal of Computers in Education 22.02 (2014): 1.

[51] Wolf, Christian. "iWeaver: towards' learning style'-based e-learning in computer science education." Proceedings of the fifth Australasian conference on Computing education-Volume 20. Australian Computer Society, Inc., 2003.

[52] Alfonseca, Enrique, et al. "The impact of learning styles on student grouping for collaborative learning: a case study." User Modeling and User-Adapted Interaction 16.3 (2006): 377-401.

[53] Pea, Clara-Ins, Jose-L. Marzo, and Josep-lluis Rosa. "Intelligent agents in a teaching and learning environment on the Web." Proceedings of the 2nd IEEE International Conference on Advanced Learning Technologies, ICALT2002. 2002.

[54] Schiaffino, Silvia, Patricio Garcia, and Analia Amandi. "eTeacher: Providing personalized assistance to e-learning students." Computers and Education 51.4 (2008): 1744-1754.

[55] Carver, Curtis A., Richard A. Howard, and William D. Lane. "Enhancing student learning through hypermedia courseware and incorporation of student learning styles." IEEE transactions on Education 42.1 (1999): 33-38.

[56] Klanja-Milievi, Aleksandra, et al. "E-Learning personalization based on hybrid recommendation strategy and learning style identification." Computers and Education 56.3 (2011): 885-899. 